\title{
Conditioning of the diaphragm by phrenic nerve pacing in primary alveolar hypoventilation
}

\author{
PEARCE G WILCOX, PETER D PARÉ, JOHN A FLEETHAM \\ From the Department of Medicine, University of British Columbia, Vancouver, Canada
}

\begin{abstract}
A patient with respiratory muscle weakness due to alveolar hypoventilation was treated with nocturnal bilateral phrenic nerve pacing for one year. Treatment was associated with a progressive increase in diaphragmatic strength and endurance.
\end{abstract}

Serial evaluation of inspiratory muscle function has shown a progressive increase in diaphragmatic contractility with chronic phrenic nerve pacing in patients with high spinal cord quadriplegia. ${ }^{2}$ We describe a patient with primary alveolar hypoventilation and associated respiratory muscle weakness who was treated with long term nocturnal bilateral phrenic nerve pacing. Diaphragmatic strength and endurance increased considerably during 12 months of pacing. A weakened but non-denervated diaphragm can be successfully conditioned by chronic phrenic nerve pacing.

\section{Case report}

A 54 year old white woman presented with a history of three previous episodes of respiratory failure requiring mechanical ventilation. She was an ex-smoker who had recurrent morning headaches. She weighed $86 \mathrm{~kg}$ and chest examination showed nothing abnormal. There was evidence of pulmonary hypertension and associated right heart failure. A chest radiograph showed prominent pulmonary arteries. The results of pulmonary function tests were within normal limits, vital capacity (VC) being $91 \%$ and total lung capacity (TLC) $89 \%$ of predicted normal and the FEV $\mathrm{F}_{1} / \mathrm{VC}$ ratio $84 \%$. Arterial blood gas measurements while she was breathing room air showed that $\mathrm{pH}$ was 7.37 , arterial oxygen tension $\left(\mathrm{PaO}_{2}\right) 7 \cdot 1 \mathrm{kPa}$ and arterial carbon dioxide tension $\left(\mathrm{PaCO}_{2}\right) \mathbf{8 . 4} \mathrm{kPa}$; after voluntary hyperventilation these changed to $\mathrm{pH} 7.51, \mathrm{PaO}_{2} 8.8 \mathrm{kPa}$, and $\mathrm{PaCO}_{2} 5.5 \mathrm{kPa}$. A sleep study showed no evidence of obstructive sleep apnoea. There was appreciable arterial oxygen desaturation (mean arterial oxygen saturation $\left(\mathrm{SaO}_{2}\right) 78 \%$ ) and hypercapnia (mean transcutaneous $\mathrm{PCO}_{2} 10.8 \mathrm{kPa}$ ), which were worst during rapid eye movement sleep. Primary alveolar hypoventilation was diagnosed. After an unsuccessful trial of respiratory stimulants and nocturnal oxygen therapy bilateral phrenic nerve pacing was instituted.

Address for reprint requests: Dr P Wilcox, Department of Medicine, University of British Columbia Health Sciences Centre Hospital, 2211 Wesbrook Mall, Vancouver, BC, Canada V6T 2B5.

Accepted 23 February 1988
Phrenic nerve pacing Bilateral intrathoracic monopolar phrenic nerve electrodes were inserted. ${ }^{3}$ Chronic nocturnal bilateral pacing was then initiated at a frequency of $10 \mathrm{~Hz}$ at a pulse train of $10 / \mathrm{min}$ with an output amplitude that had been shown to produce the maximum tidal volume. There was a progressive improvement in her symptoms with resolution of right heart failure and appreciable reduction in the size of the pulmonary arteries on the chest radiograph. Follow up estimations of arterial blood gases with the patient breathing room air showed that $\mathrm{pH}$ was $7.37, \mathrm{Po}_{2} 10.8 \mathrm{kPa}$, and $\mathrm{PCO}_{2}$ $5 \mathrm{kPa}$. A repeat overnight sleep study, performed with bilateral phrenic nerve pacing, showed substantial decrease in nocturnal hypoxaemia (mean $\mathrm{SaO}_{2} 93 \%$ ) and hypercapnia (mean transcutaneous $\mathrm{PcO}_{2} 6.0 \mathrm{kPa}$ ).

Her body weight remained unchanged during the one year follow up period.

Assessment of respiratory muscles Respiratory muscle strength was assessed before placement of the phrenic nerve electrodes, before the start of pacing, and six months and one year after the start of pacing (table 1). Maximal inspiratory pressure (PI max), maximal expiratory pressure (PE max), and maximal transdiaphragmatic pressure (Pdi max) were measured by the techniques reported by Black and Hyatt ${ }^{4}$ and Laporta and Grassino ${ }^{5}$ respectively. Pdi max was measured when the patient performed a maximal inspiratory effort from functional residual capacity (FRC). Pi max, PE max, and Pdi max were all appreciably reduced before phrenic nerve pacing, which suggests significant respiratory muscle weakness. There was no clinical evidence of generalised myopathy and both electrophysiological tracings and a deltoid muscle biopsy specimen were normal. There was a progressive increase in PI max and Pdi max over the one year period of phrenic nerve pacing, PE max remaining unchanged. Pdi max was also measured after a three hour period of bilateral phrenic nerve pacing before long term pacing and after one year of nocturnal bilateral phrenic nerve pacing. In the initial studies there was an appreciable decline in vital capacity and Pdi max after three hours of pacing (table 2). Similar changes were not seen after one year.

\section{Discussion}

This case report confirms the efficacy of nocturnal phrenic nerve pacing in the treatment of primary alveolar hypoventilation. ${ }^{6}$ Furthermore, the results of the inspiratory muscle testing suggest that chronic phrenic nerve pacing improves both the strength and the endurance of the diaphragm. 
Table 1 Results ( $\left.\mathrm{cm} \mathrm{H}_{2} \mathrm{O}\right)$ of respiratory muscle tests before and after chronic bilateral phrenic nerve pacing

\begin{tabular}{|c|c|c|c|c|c|}
\hline & \multirow{2}{*}{$\begin{array}{l}\text { Predicted } \\
\text { normal }\end{array}$} & \multirow{2}{*}{$\begin{array}{l}\text { Before } \\
\text { pacing }\end{array}$} & \multicolumn{3}{|c|}{ After pacing } \\
\hline & & & Baseline & $6 \mathrm{mo}$ & $l y$ \\
\hline $\begin{array}{l}\text { PI max } \\
\text { PE max } \\
\text { Pdi max }\end{array}$ & $\begin{array}{l}79 * \\
148 * \\
180(14) \dagger\end{array}$ & $\begin{array}{l}26 \\
50 \\
42\end{array}$ & $\begin{array}{l}25 \\
52 \\
45\end{array}$ & $\frac{34}{56}$ & $\begin{array}{l}58 \\
54 \\
74\end{array}$ \\
\hline
\end{tabular}

"From Black and Hyatt."

†From Laporta and Grassino: mean (SD) for young adults. ${ }^{5}$

PI max - maximal inspiratory pressure; PE max-maximal expiratory pressure; Pdi max-maximal transdiaphragmatic pressure.

Table 2 Vital capacity and maximal transdiaphragmatic pressure (Pdi max) before and after three hours of bilateral phrenic $\frac{\dot{A}}{\omega}$ nerve pacing before and after one year of nocturnal pacing

\begin{tabular}{llllll}
\hline & \multicolumn{2}{l}{ Vital capacity $(l)(\%$ pred $)$} & & \multicolumn{2}{l}{ Pdi $\max \left(\mathrm{cm} \mathrm{H}_{2} \mathrm{O}\right)$} \\
\cline { 2 - 3 } & Before & After & Before & After \\
\hline Baseline & $2.6(79 \%)$ & $2.4(73 \%)$ & & 45 & 23 \\
After 1 y pacing & $2.8(85 \%)$ & $2.8(85 \%)$ & 74 & 66 \\
\hline
\end{tabular}

Primary alveolar hypoventilation is a syndrome of unknown cause characterised by hypoventilation and normal lung function. There has been limited evaluation of respiratory muscle function in this condition, though a reduced maximal voluntary ventilation has been noted in one patient.' Our patient did show inspiratory muscle weakness, though her ability to restore her arterial $\mathrm{PCO}_{2}$ with voluntary hyperventilation suggests that this was not the primary cause of her chronic hypoventilation. The inspiratory muscle weakness is probably due to deconditioning of the inspiratory muscles secondary to chronic hypoventilation.

There are several reports that suggest that chronic phrenic nerve pacing conditions the diaphragm. Three patients with high cervical cord quadriparesis showed an upward shift in the minute ventilation-frequency curve and an increase in Pdi after one year of phrenic nerve pacing.' Bilateral phrenic nerve pacing was initiated six months after cervical injury in a 59 year old quadriplegic man. ${ }^{2}$ The force of diaphragm contraction was assessed serially by measurement of Pdi during stimulation of each nerve over a range of frequencies. There was a progressive upward shift in the force-frequency relationship.

Inspiratory muscle endurance, defined as the capacity of the inspiratory muscles to sustain work, has been shown to increase after inspiratory resistive training in normal subjects $^{8}$ and in patients with chronic obstructive lung disease ${ }^{9}$ and quadriplegia. ${ }^{10}$ Quadriplegic patients show a progressive increase in respiratory muscle endurance with chronic phrenic nerve pacing.' Formal evaluation of inspiratory muscle endurance was not performed in our patient. In our initial studies, however, there was a reduction in vital capacity and Pdi max after three hours of phrenic nerve pacing, which did not occur after 12 months of pacing. One possible explanation for this improvement is an alteration of diaphragmatic fibre type. An increase in fatigue resistant fibres has been detected by histochemical studies of the diaphragm in quadriplegic patients after long term $\stackrel{\mathbb{\Phi}}{\frac{\mathbb{C}}{2}}$ phrenic nerve pacing.'

This work was supported by the British Columbia Lung 9 Association, and PW had a Canadian Lung Association research fellowship.

\section{References}

1 Glenn WWL, Hogan JF, Loke JSO, Ciesielski TE, Phelps ML, Rowedder $R$. Ventilatory support by pacing of the conditioned diaphragm in quadriplegia. N Engl J Med 1984;310:1150-5.

2 Nochomovitz M, Hopkins $M$, Brodkey J, Montenegro $H$, Mortimer JT, Cherniack N. Conditioning of the diaphragm with phrenic nerve stimulation after prolonged disuse. Am Rev Respir Dis 1984;130:685-8.

3 Glenn WWL, Hogan JF, Phelps ML. Ventilatory support of the quadriplegic patient with respiratory paralysis by diaphragm pacing. Surg Clin North Am 1980;60:1055-78.

4 Black LF, Hyatt RE. Maximal respiratory pressures: normal values and relationship to age and sex. Am Rev Respir Dis? 1969;99:696-702.

5 Laporta D, Grassino A. Assessment of transdiaphragmatic pressure in humans. J Appl Physiol 1985;58:1469-76.

6 Hyland RH, Jones NL, Powles ACP, Lenkie SCM, Vanderlinden RG, Epstein SW. Primary alveolar hypoventilation treated with nocturnal electrophrenic respiration. Am Rev Respir Dis 1978;117:165-72.

7 Naughton J, Black R, Welch M. Central alveolar hypoventilation: a case report. Am Rev Respir Dis 1971;103:557-65.

8 Leith DE, Bradley $M$. Ventilatory muscle strength and endurance $N$ training. J Appl Physiol 1976;41:508-16.

9 Pardy RL, Rivington RN, Despas PJ, Macklem PT. The effects of inspiratory muscle training on exercise performance in chronice airflow limitation. Am Rev Respir Dis 1981;123:426-33.

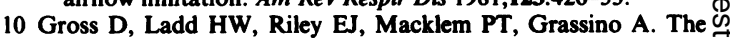
effect of training on strength and endurance of the diaphragm in quadriplegia. Am J Med 1980;68:27-35. 